\title{
RESEARCH
}

Open Access

\section{Use of action planning to increase provision of smoking cessation care by general practitioners: role of plan specificity and enactment}

Marjolein EA Verbiest ${ }^{1 *}$, Justin Presseau ${ }^{2}$, Niels H Chavannes ${ }^{1}$, Margreet Scharloo ${ }^{3}$, Ad A Kaptein ${ }^{3}$, Willem JJ Assendelft ${ }^{1,4}$ and Mathilde R Crone ${ }^{1}$

\begin{abstract}
Background: Strategies are needed to help general practitioners (GPs) promote smoking cessation as recommended by guidelines. This study examines whether the quality of action planning among GPs improves their provision of smoking cessation care.

Methods: The effectiveness of a 1-h training programme was examined in a cluster randomised controlled trial in which 49 GPs participated. GPs who followed the training (intervention group; $n=25$ ) formulated action plans related to i) enquiring about smoking, ii) advising to quit smoking, and iii) arranging follow-up for smokers motivated to quit. GPs also formulated a coping plan for encountering smokers not motivated to quit. The quality of these plans (plan specificity) was rated and, 6 weeks after the training, GPs reported on the performance of these plans (plan enactment). Multilevel regression analyses were used to examine the effects of plan specificity and plan enactment on patient-reported smoking cessation activities of the GPs in the intervention group ( $n=1,632$ patients) compared with the control group ( $n=1,769$ patients).

Results: Compared to the control group, GPs who formulated a highly specific action plan during the training asked their patients about smoking more often after the training compared to prior to the training $(\mathrm{OR} 2.11,95 \% \mathrm{Cl}$ 1.51-2.95). GPs were most likely to have asked patients about smoking after the training compared to prior to the training when they had enacted a highly specific formulated action plan (OR 3.08,95\% Cl 2.04-4.64). The effects of GP plan specificity and plan enactment on asking patient about smoking were most prominent among GPs who, at baseline, intended to provide smoking cessation care.

Conclusions: A highly specific action plan formulated by a GP on when, how, and by whom patients will be asked about smoking had a positive effect on GPs' asking patients about smoking, especially when these professionals also reported to have enacted this plan. This effect was most prominent among GPs who intended to provide smoking cessation care prior to the intervention. Training in devising personalised coping plans is recommended to further increase GPs' provision of advice to quit smoking and arranging follow-up support to quit smoking.
\end{abstract}

Keywords: General practise, Smoking cessation care, Implementation, Action planning

\footnotetext{
* Correspondence: m.e.a.verbiest@lumc.nl

${ }^{1}$ Department of Public Health and Primary Care, Leiden University Medical

Centre, PO Box 9600, 2300, RC, Leiden, The Netherlands

Full list of author information is available at the end of the article
} 


\section{Background}

Current guidelines recommend that general practitioners (GPs) routinely ask patients about smoking, advise them to quit, assess their motivation to quit, assist them with quitting, and arrange follow-up quit smoking support (the 5-A Model) [1,2]. However, GPs report difficulties when translating these guidelines into practise [3-7], resulting in a substantial gap between evidence and practise. A study in Dutch general practise showed that $79 \%$ of all smokers and $40 \%$ of smokers who discussed smoking with their GP did not receive stop-smoking advice [8]. The development of strategies that facilitate the implementation of guidelinerecommended smoking cessation care may result in more patients being advised to quit and being provided with evidence-based quit-smoking support and, ultimately, giving up smoking [9-11].

Strategies to facilitate the implementation of evidencebased clinical guidelines often focus on influencing the behaviour of the health-care professionals [12-15]. Efforts to change the clinical behaviour of health-care professionals often involve didactic modes of delivery aimed at educating these professionals [13-15]. However, this approach implies a lack of knowledge and assumes that additional knowledge will change the behaviour of health-care providers, neither of which may necessarily be true. In fact, enhancing knowledge alone may not be the best, or even an adequate strategy, to influence the clinical behaviour of health-care professionals [16]. Similarly, the motivation and/or the beliefs of GPs to routinely adopt evidencebased guidelines are not always a reliable predictor of the routine implementation of these guidelines [17].

Psychological theories may provide a basis for identifying the predictors of GP behaviour and of behaviour change [16]. Clinical practise is a form of human behaviour that is sensitive to theory-based strategies that have proven effective in patient samples [18-22]. However, a systematic review showed that only a minority of the 235 interventions that previously aimed to facilitate guideline implementation by health-care professionals actually used those theory-based strategies [12].

One of the well-established theory-based strategies (albeit in other populations) is the self-formation of 'conditional plans', such as action plans and coping plans [23,24]. Action plans link a situational cue to behaviour in order to promote behaviour change and habit formation, e.g. 'if $X$ occurs (if the patient visits me because of a cough more than three times a year), then I will do $Y$ (I will advise the patient to quit smoking)'. Coping plans anticipate potential barriers to behaviour change which impede action plans from working. Such plans aim to bridge the gap between the individual's intention to perform the behaviour and the actual performance of that behaviour $[25,26]$.

The mechanisms that underlie the effectiveness of action and coping plans involve a heightened accuracy and speed of detecting the contextual cue for performing the intended behaviour [27-30]. Plans that are more specific are suggested to result in a greater improvement of the intended behaviour compared to incomplete or vague plans [31,32]. In addition, studies have shown that individuals who act according to their formulated action plans (i.e. plan enactment) are more likely to benefit from their plans, e.g. enacting an action plan to remove all tobacco products results in a higher likelihood to actually quit smoking $[33,34]$. The effects of plan specificity and enactment on behaviour are strongest among those individuals who are the most motivated to change the intended behaviour [31-33,35].

It has been shown that planning predicts the clinical behaviour of GPs in various clinical conditions [36-38]. Moreover, an intervention study showed that incorporating planning in postgraduate education increased the use of a practitioner-guided procedure among mental health professionals [35]. However, to our knowledge, no studies have examined whether planning improves the provision of evidence-based smoking cessation care by GPs.

The present study incorporates action planning within a training session for GPs, aimed at increasing their provision of smoking cessation tasks as recommended in clinical guidelines, including asking patients about smoking, advising them to quit, and arranging follow-up quit smoking support for smokers who are motivated to quit. Because GPs often indicate that patients' lack of motivation to quit may act as a barrier to the provision of guidelinerecommended smoking cessation care $[5,39,40]$, GPs also formulated a coping plan to address this potential barrier.

Based on the reported positive effects of action planning in patient samples [41-43], we hypothesised that GP action planning would improve the performance of these smoking cessation tasks. Secondly, we hypothesised that formulating a coping plan for smokers who are not motivated to quit provided GPs with a solution for this type of barrier, thereby increasing the provision of smoking cessation care for this group [38,44-48]. Since the present GP training includes multiple behaviour change strategies, we also examined the nature of action planning including plan specificity and plan enactment. In line with the previous findings on plan specificity and self-reported plan enactment [31-35], we hypothesised that GPs who formulated a highly specific plan and reported a high level of plan enactment would be more likely to provide smoking cessation care post-training. Finally, we hypothesised that these effects would be most evident among GPs with high intention to routinely implement smoking cessation care prior to the training.

\section{Methods}

\section{Design and intervention}

The present paper reports the results of a two-group cluster randomised controlled trial in general practise. 
GPs were randomly assigned to either the intervention or control condition. The intervention entailed a $1-\mathrm{h}$ individual training session for GPs in the delivery of smoking cessation care. The training was based on behaviour change techniques related to methods that underlie the current Dutch guidelines for treating tobacco addiction (the 5-A model [2,49]): 1) GPs' implementation barriers were identified, 2) GPs were provided with a state-of-the-art evidence about the effectiveness of smoking cessation care, 3) GPs' motivation to routinely implement the guideline was identified and improved using motivational interviewing techniques, 4) GP instruction was provided and tailored to the identified implementation barriers, and 5) GPs were given the opportunity to receive additional feedback support. Previously, the effects of the multicomponent training on GPs' provision of smoking cessation care were tested and reported elsewhere [50]. Action planning was one of the components of the GP training, and our initial RCT did not provide insight into the effects of this single behaviour change technique. Therefore, the present study focuses on a further examination of the effects and nature of action planning among the trained GPs.

\section{Participants}

During the study period (January-August 2011), 25 GPs received a 1 -h training programme that incorporated action planning. At baseline (pre-intervention), these 25 GPs saw 1,002 patients, of whom 195 (19.5\%) were smokers. During post-intervention, the same GPs saw a different group of 630 patients, of whom 98 (15.6\%) were smokers. In the control condition, 24 GPs and 1,769 patients (baseline: 1,066, post-intervention: 703) were included, of whom $384(21.7 \%)$ were smoking patients (baseline: 238 (22.3\%), post-intervention: $146(20.8 \%))$.

\section{Measurements \\ GP intention}

Six weeks prior to the training programme, GPs rated their intention to implement guideline-recommended smoking cessation care on a 4-point scale ('no intention to routinely implement smoking cessation treatment within 6 months' (0), 'intention to routinely implement smoking cessation treatment within 6 months' (1), 'intention to routinely implement smoking cessation care within 1 month' (2), and 'already routinely implemented smoking cessation treatment' (3). To facilitate testing of the hypotheses, we used a post-hoc categorisation in line with the principles from the health action process approach [51] to classify GPs into three groups depending on their response to the question about their intention: 1) 'GP pre-intenders' (answer category 0; 4 GPs, 393 patients), 'GP intenders' (answer category 1 and 2 combined; 14 GPs, 2,211 patients), and 'GP actors' (answer category 3; 7 GPs, 797 patients).

\section{Patient-reported provision of smoking cessation care}

During the 3 weeks prior to and after the GP training programme, all patients completed a questionnaire immediately after their GP consultation in which they rated their GP's smoking cessation activities during that consultation. This questionnaire included the following items: 'Did your GP ask you about smoking during the consultation?', 'Did your GP advise you to quit during the consultation?', and 'Did your GP refer you to any kind of follow-up quit smoking support during the consultation'? For each item, patients could answer 'Yes' (1) or 'No' (0).

\section{Action planning}

During the GP training programme, action planning was assessed based on the separate plans formulated by the GP for a) identifying smokers and b) advising smokers to quit. GPs wrote down who was going to perform the activity, when the activity was going to be performed, and how the activity was going to be registered in the patient's electronic health record. In addition, GPs formulated an action plan for c) arranging follow-up for smokers who are motivated to quit and a coping plan for d) arranging follow-up for smokers who are not motivated to quit. In these plans, GPs formulated the what, who, and how of each plan. This method is comparable to that used in similar studies with patient samples [31].

\section{Specificity of GP plans}

The degree of specificity of each of the components of the GPs' plans (who, when, what, and how) was assessed using a rating method based on previous studies $[31,32,34]$. The who component of the plans was rated as not completed (0) or completed (1). The when, what, and how components of the plans were rated on a 4-point scale; components were rated as not completed (0) if GPs did not write down any plans, and components were rated as being general (1) when GPs described them in rather general terms, e.g. 'I will ask my patients about their smoking during the consultation'. Components that were specified with moderate precision were rated as being moderately specific (2), e.g. 'I will ask my patients about their smoking, routinely once a year'. A component was rated as being highly specific (3) when GPs specified their future action with a sufficient amount of precision, e.g. 'I will ask my patients about their smoking when they present with smoking-related complaints during the consultation'.

Analyses of the when component showed that GPs specified either a particular moment (e.g. during the consultation), or a particular type of patient (e.g. patients with smoking-related complaints), or both; therefore, we decided to rate both these types of specifications. As a result, the total specificity score for the first two action plans (asking about smoking and advising to quit) ranged 
from 0 to 10, and for the third action plan (dealing with smokers who were motivated to quit) and the coping plan (dealing with smokers who were not motivated to quit), scores ranged from 0 to 7 (Appendix 1).

Two researchers independently rated the specificity of all components of the GPs' plans. Kappa statistics were used to estimate the inter-rater agreement; this resulted in a high level of agreement between the two researchers for the total specificity scores of the GPs' plans: i.e. for asking about smoking 0.998 (95\% CI 0.995-0.999), for advising to quit 0.940 ( $95 \%$ CI $0.864-0.973$ ), for arranging follow-up for smokers who are motivated to quit 0.945 (95\% CI 0.850-0.978), and for arranging follow-up for smokers not motivated to quit 0.962 (95\% CI $0.907-$ 0.984). These high kappa coefficients are probably due to the type of rating method used. Disagreements were discussed until consensus was achieved. For analyses, the GPs' total plan specificity scores were categorised into low (1) and high (2) scores, using the mean score as a cut-off.

\section{Enactment of GP plans}

After the GP training, we were interested in providing the GPs in the intervention group with their self-formulated if-then plans and ask them if they had the opportunity to enact them. Therefore, 6 weeks after the GP training programme, via a postal questionnaire, the GPs were asked to report the extent of plan enactment (response rate $76 \% ; n=19$ ). In this questionnaire, each GP was provided with the four plans that they had previously formulated. GPs were asked to rate the extent to which they had enacted each plan using a 5-point scale: 'plan not enacted, not intending to enact in the future' (0), 'plan not enacted, intending to enact within 1 month'(1), 'plan not enacted, intending to enact within a week' (2), 'plan partly enacted' (3),'plan fully enacted' (4). For missing data, a negative scenario was applied which assumed that GPs who did not complete the questionnaire did not enact their plans (score 0 ). For the analyses, scores for plan enactment were categorised into low (1) and high (2) scores using the mean score as a cut-off.

\section{Statistical analysis}

Descriptive statistics were used for the characteristics of the GPs and for scores on specificity of the GP plan and on plan enactment. To test our hypotheses, we linked GP the data with patient data and analysed these using twolevel logistic regression analyses (generalised estimating equations), including the data at the GP and patient level.

In our model, data at the GP level included scores on plan specificity and plan enactment as independent variables. To examine the main effects of these variables on GPs' provision of smoking cessation care (patient-reported), all patients were classified into three categories, i.e. patients who had a consultation with a GP who had formulated a highly specific plan/reported a high level of plan enactment (2), patients who had a consultation with a GP who had formulated a general plan/reported a low level of plan enactment (1), and patients who had a consultation with a GP within the control condition (0).

Data at the patient level included GPs' provision of smoking cessation care, as reported by patients, as dependent variables, including being asked about smoking, being advised to quit, and being provided with quit smoking follow-up. Patient-reported smoking cessation care was included as a dichotomous variable $(1=$ yes, $0=$ no). The model was adjusted for differences between characteristics of the patients who visited the GPs at baseline and those who consulted the GPs post-intervention (gender, cultural background, and smoking status).

Univariate analysis was used to examine the main effects of GP plan specificity and GP-reported plan enactment on their provision of smoking cessation care (as reported by patients). In addition, interaction analysis was used to examine whether or not the effects of GP plan specificity on the delivery of care depended on the extent of GP plan enactment. Finally, subgroup analyses were performed to examine whether the effects of GP plan specificity and plan enactment on delivered smoking cessation care, differed between GPs with different baseline intentions to routinely implement smoking cessation care. In all models, we included time (baseline (0)/post-intervention (1)) by group (control group (0)/ low plan specificity or low plan enactment (1)/high plan specificity or high plan enactment (2)) interaction effects since we included different cohorts of patients at baseline and post-intervention.

This study was approved by the Medical Ethical Board of the Leiden University Medical Centre (P10.125).

\section{Results}

\section{Sample characteristics}

Of the 49 participating GPs, 28 (57.1\%) were men and $38(77.6 \%)$ had worked more than 10 years as a GP; in addition, the majority worked on average $38 \mathrm{~h} /$ week and had a mean age of 50 years. Most of these GPs worked in collaboration with one $(n=33 ; 67.3 \%)$ or two $(n=12$; $24.5 \%)$ practise nurses. None of the GP characteristics were significantly different between the intervention and control condition. A detailed overview of the background characteristics of participating GPs and patients is reported elsewhere [50].

\section{Specificity and enactment of GP plans}

Descriptive data with regard to the specificity of GPs' plans are presented in Table 1. Most GPs completed all components of their action plans and coping plan. With regard to the 'when' component, most GPs described $a$ type of moment for which they planned to ask about 
Table 1 Specificity and enactment of GPs' plans to provide guideline-recommended smoking cessation care

\begin{tabular}{|c|c|c|c|c|}
\hline \multirow[b]{2}{*}{ Plan specificity (score) } & \multicolumn{3}{|l|}{ GP action plans } & \multirow{2}{*}{$\begin{array}{l}\text { GP coping plan } \\
\text { Arrange follow-up unmotivatec } \\
\text { to quit ( } n=25,100 \%)\end{array}$} \\
\hline & $\begin{array}{l}\text { Ask about smoking } \\
(n=25,100 \%)\end{array}$ & $\begin{array}{l}\text { Advise to quit } \\
(n=25,100 \%)\end{array}$ & $\begin{array}{l}\text { Arrange follow-up motivated } \\
\text { to quit }(n=25,100 \%)\end{array}$ & \\
\hline Who, completed (1) & $24(96.0 \%)$ & $24(96.0 \%)$ & $22(88.0 \%)$ & $21(84.0 \%)$ \\
\hline \multicolumn{5}{|l|}{ When (moment)/what } \\
\hline Not completed (0) & $6(24.0 \%)$ & $6(24.0 \%)$ & $2(8.0 \%)$ & $3(12.0 \%)$ \\
\hline General (1) & $13(52.0 \%)$ & $14(56.0 \%)$ & $6(24.0 \%)$ & $8(32.0 \%)$ \\
\hline Medium specific (2) & $3(12.0 \%)$ & $4(16.0 \%)$ & $13(52.0 \%)$ & $5(20.0 \%)$ \\
\hline Highly specific (3) & $3(12.0 \%)$ & $1(4.0 \%)$ & $4(16.0 \%)$ & $9(36.0 \%)$ \\
\hline Total score, M (SD) & $1.12(0.93)$ & $1.00(0.76)$ & $1.76(0.83)$ & $1.80(1.08)$ \\
\hline \multicolumn{5}{|l|}{ When (type patient) } \\
\hline Not completed (0) & $20(80.0 \%)$ & $20(80.0 \%)$ & NA & NA \\
\hline General (1) & $0(0.0 \%)$ & $1(4.0 \%)$ & NA & NA \\
\hline Medium specific (2) & $1(4.0 \%)$ & $3(12.0 \%)$ & NA & NA \\
\hline Highly specific (3) & $4(16.0 \%)$ & $1(4.0 \%)$ & NA & NA \\
\hline Total score, M (SD) & $0.56(1.16)$ & $0.40(0.87)$ & NA & NA \\
\hline \multicolumn{5}{|l|}{ How register } \\
\hline Not completed (0) & $2(8.0 \%)$ & $1(4.0 \%)$ & $4(16.0 \%)$ & $5(20.0 \%)$ \\
\hline General (1) & $4(16.0 \%)$ & $5(20.0 \%)$ & $7(28.0 \%)$ & $6(24.0 \%)$ \\
\hline Medium specific (2) & $2(8.0 \%)$ & $6(24.0 \%)$ & $8(32.0 \%)$ & $10(40.0 \%)$ \\
\hline Highly specific (3) & $17(68.0 \%)$ & $13(52.0 \%)$ & $6(24.0 \%)$ & $4(16.0 \%)$ \\
\hline Total score, M (SD) & $2.36(1.04)$ & $2.24(0.93)$ & $1.64(1.04)$ & $1.52(1.01)$ \\
\hline Total specificity score, M (SD)a & $5.00(2.10)$ & $4.60(1.66)$ & $4.28(1.79)$ & $4.12(2.03)$ \\
\hline \multicolumn{5}{|l|}{ Plan enactment (score) } \\
\hline $\begin{array}{l}\text { Plan not enacted, not intending to in } \\
\text { the future }(0)\end{array}$ & $10(40.0 \%)$ & $12(48.0 \%)$ & $11(44.0 \%)$ & $15(60.0 \%)$ \\
\hline $\begin{array}{l}\text { Plan not enacted, intending to within } \\
1 \text { month (1) }\end{array}$ & $2(8.0 \%)$ & $2(8.0 \%)$ & $0(0.0 \%)$ & $1(4.0 \%)$ \\
\hline $\begin{array}{l}\text { Plan not enacted, intending to within } \\
\text { a week (2) }\end{array}$ & $0(0.0 \%)$ & $0(0.0 \%)$ & $0(0.0 \%)$ & $1(4.0 \%)$ \\
\hline Plan partly enacted (3) & $8(32.0 \%)$ & $6(24 \%)$ & $3(12.0 \%)$ & $3(12.0 \%)$ \\
\hline Plan fully enacted (4) & $5(20.0 \%)$ & $5(20.0 \%)$ & $11(44.0 \%)$ & $5(20.0 \%)$ \\
\hline Total enactment score, $\mathrm{M}(\mathrm{SD})^{\mathrm{b}}$ & $1.84(1.70)$ & $1.60(1.73)$ & $2.12(1.94)$ & $1.28(1.72)$ \\
\hline
\end{tabular}

GPs general practitioners, $M$ mean, $S D$ standard deviation, $N A$ not applicable.

aTotal specificity scores for action plans 'asking about smoking' and 'advising to quit' could range from 0 to 10 and for the action and coping plans 'arranging follow-up for smokers motivated to quit' and 'arranging follow-up for smokers unmotivated to quit' could range from 0 to 7.

${ }^{\mathrm{b}}$ Total enactment scores could range from 0 to 4.

smoking or advise to quit, instead of a type of patient for who they planned to provide this care. Only a minority of the GPs described the type of moment or the type of patient highly specific, such as 'I'll ask my patient about smoking, when I make a risk profile of the patient' (moment) or 'I'll ask all patients with a chronic illness about smoking' (patient). Only a few GPs described highly specific what they planned to do when they would encounter a smoker who is motivated or unmotivated to quit, such as 'When I encounter a smoker who is motivated to quit, I will discuss the (dis)advantages of quitting, motivation to quit, and I will make a quit plan' or 'When I encounter a smoker who is not motivated to quit, I'll ask the patient's permission to discuss their smoking behaviour again during the next consultation'. Most GPs described highly specific how they planned to register the activities in the electronic patient record, for example using the 'International Classification of Primary Care'. Most GPs who formulated a highly specific action plan for asking patients about smoking also reported a high level of plan enactment $(n=6 / 9,66.7 \%)$. Similar associations were found between GP plan specificity and plan 
enactment in the other action and coping plans. However, some GPs who formulated general plans reported a high level of plan enactment and vice versa.

\section{Effect of GP plan specificity and enactment on provision of smoking cessation care}

Tables 2 and 3 show the effects of plan specificity and plan enactment, respectively, on GPs' provision of smoking cessation care, contrasting patients seen by GPs in the control group. With regard to GPs' task of 'asking about smoking', all patients (smokers and non-smokers) were included in the analyses but classified into patients seen by a GP 1) 'in the control condition', 2) 'who formulated a general action plan', and 3) 'who formulated a highly specific action plan'. With regard to GPs' tasks of 'advising to quit' and 'arranging follow-up', we present the results for the subsets of patients that reported being a smoker.

After the adjustment for clustering effects and patient characteristics, we found a significant time-by-group interaction effect of action planning on GPs asking patient about smoking (Table 2); compared to the changes on GPs' asking about smoking in the control group, patients in the intervention group who visited their GP postintervention reported being asked about their smoking status more often than patients who visited their GP prior to action planning. We only found a significant effect for highly specific action plans (OR 2.11, 95\% CI 1.51-2.95). Similarly, we only found a positive time-by-group interaction effect of high plan enactment on GPs' asking about smoking (Table 3; OR 3.04, 95\% CI 2.10-4.41). Further analyses showed that the effect of high plan enactment on GP asking about smoking differed according to the degree of specificity of the action plan $(p<0.001)$. Compared to the changes in time in the control group, patients who visited a GP who formulated a highly specific action plan and reported a high level of plan enactment post-intervention were asked more often about their smoking behaviour compared to prior to the intervention (OR 3.08, 95\% CI 2.04-4.64) (Table 4).

With regard to GPs' plans to routinely advise smokers to quit and to arrange a follow-up for smokers who are motivated or not motivated to quit, no significant main or interaction effects of GP plan specificity and plan enactment were found on the delivery of smoking cessation care, as reported by the patients (Tables 2 and 3).

\section{GP intention}

Table 5 presents the results of the analyses of three subgroups of patients, namely patients who consulted a GP who reported at baseline to be 1) a 'pre-intender', 2) an

Table 2 Effect of GP plan specificity on the provision of smoking cessation activities (patient-reported) ${ }^{a}$

\begin{tabular}{|c|c|c|c|c|c|}
\hline \multirow[b]{2}{*}{ All patients $(n=3,401)$} & \multicolumn{2}{|c|}{ Baseline } & \multicolumn{2}{|c|}{ Post-intervention } & \multirow[t]{2}{*}{ Time $\times$ group OR $(95 \% \mathrm{Cl})$} \\
\hline & $n$ total & $\%$ asked & $n$ total & $\%$ asked & \\
\hline \multicolumn{6}{|l|}{ Asked about smoking } \\
\hline Highly specific GP plan & 731 & $29.9 \%$ & 437 & $41.0 \%$ & $2.11(1.51-2.95)^{* *}$ \\
\hline Low specific GP plan & 271 & $40.3 \%$ & 193 & $42.8 \%$ & $1.29(0.82-2.03)$ \\
\hline Control group & 1,066 & $40.8 \%$ & 703 & $37.1 \%$ & 1 \\
\hline All smokers $(n=665)$ & $n$ total & $\%$ advised & $n$ total & $\%$ advised & \\
\hline \multicolumn{6}{|l|}{ Advised to quit } \\
\hline Highly specific GP plan & 93 & $37.1 \%$ & 49 & $53.3 \%$ & $2.28(0.81-6.40)$ \\
\hline Low specific GP plan & 102 & $43.3 \%$ & 49 & $33.3 \%$ & $0.62(0.21-1.80)$ \\
\hline Control group & 229 & $43.8 \%$ & 143 & $44.1 \%$ & 1 \\
\hline Smokers motivated to quit $(n=214)$ & $n$ total & $\%$ arranged & $n$ total & $\%$ arranged & \\
\hline \multicolumn{6}{|l|}{ Arranged for follow-up } \\
\hline Highly specific GP plan & 39 & $15.4 \%$ & 20 & $40.0 \%$ & $\mathrm{~b}$ \\
\hline Low specific GP plan & 21 & $28.6 \%$ & 11 & $18.2 \%$ & $\mathrm{~b}$ \\
\hline Control group & 71 & $18.3 \%$ & 52 & $9.6 \%$ & 1 \\
\hline Smokers not motivated to quit $(n=408)$ & $n$ total & $\%$ arranged & $n$ total & $\%$ arranged & \\
\hline \multicolumn{6}{|l|}{ Arranged for follow-up } \\
\hline Highly specific GP plan & 39 & $20.5 \%$ & 21 & $14.3 \%$ & $\mathrm{~b}$ \\
\hline Low specific GP plan & 82 & $4.9 \%$ & 38 & $7.9 \%$ & $b$ \\
\hline Control group & 142 & $4.9 \%$ & 86 & $10.5 \%$ & 1 \\
\hline
\end{tabular}

GPs general practitioners, $O R$ odds ratio, $C l$ confidence interval.

${ }^{a}$ Generalised estimating equations adjusted for clustering and patient characteristics.

${ }^{b}$ Analyses not possible due to the sparseness of data.

${ }^{*} p<0.01,{ }^{* *} p<0.001$. 
Table 3 Effect of GP plan enactment on the provision of smoking cessation activities (patient-reported) ${ }^{a}$

\begin{tabular}{|c|c|c|c|c|c|}
\hline \multirow[b]{2}{*}{ All patients $(n=3,401)$} & \multicolumn{2}{|c|}{ Baseline } & \multicolumn{2}{|c|}{ Post-intervention } & \multirow[t]{2}{*}{ Time $\times$ group OR $(95 \% \mathrm{Cl})$} \\
\hline & $n$ total & $\%$ asked & $n$ total & $\%$ asked & \\
\hline \multicolumn{6}{|l|}{ Asked about smoking } \\
\hline High GP plan enactment & 459 & $34.6 \%$ & 314 & $55.7 \%$ & $3.04(2.10-4.41)^{* *}$ \\
\hline Low GP plan enactment & 543 & $31.1 \%$ & 316 & $27.3 \%$ & $1.01(0.68-1.49)$ \\
\hline Control group & 1,066 & $40.8 \%$ & 703 & $37.1 \%$ & 1 \\
\hline All smokers $(n=665)$ & $n$ total & $\%$ advised & $n$ total & $\%$ advised & \\
\hline \multicolumn{6}{|l|}{ Advised to quit } \\
\hline High GP plan enactment & 63 & $57.1 \%$ & 33 & $66.7 \%$ & $0.85(0.27-2.65)$ \\
\hline Low GP plan enactment & 132 & $39.4 \%$ & 65 & $46.2 \%$ & $1.52(0.58-3.99)$ \\
\hline Control group & 229 & $43.8 \%$ & 143 & $44.1 \%$ & 1 \\
\hline Smokers motivated to quit $(n=214)$ & $n$ total & $\%$ arranged & $n$ total & $\%$ arranged & \\
\hline \multicolumn{6}{|l|}{ Arranged for follow-up } \\
\hline High GP plan enactment & 35 & $17.1 \%$ & 16 & $18.1 \%$ & b \\
\hline Low GP plan enactment & 25 & $24.0 \%$ & 15 & $26.7 \%$ & b \\
\hline Control group & 71 & $18.3 \%$ & 52 & $9.6 \%$ & 1 \\
\hline Smokers not motivated to quit $(n=408)$ & $n$ total & $\%$ arranged & $n$ total & $\%$ arranged & \\
\hline \multicolumn{6}{|l|}{ Arranged for follow-up } \\
\hline High GP plan enactment & 35 & $17.1 \%$ & 15 & $13.3 \%$ & $\mathrm{~b}$ \\
\hline Low GP plan enactment & 86 & $7.0 \%$ & 44 & $9.1 \%$ & $\mathrm{~b}$ \\
\hline Control group & 142 & $4.9 \%$ & 86 & $10.5 \%$ & 1 \\
\hline
\end{tabular}

GPs general practitioners, OR odds ratio, $\mathrm{Cl}$ confidence interval.

${ }^{a}$ Generalised estimating equations adjusted for clustering and patient characteristics.

${ }^{\mathrm{b}}$ Analyses not possible due to the sparseness of data.

${ }^{*} p<0.01,{ }^{* *} p<0.001$

'intender', or 3) an 'actor' regarding the implementation of smoking cessation care. For each of these subgroups, we explored whether a more specific action plan or a higher plan enactment was associated with a significant increase in the percentage of patients reporting being asked about smoking. Consistent with our hypothesis, we found no positive main effects of GP plan specificity and GP plan enactment among those patients who visited GPs who, at baseline, had already fully implemented smoking cessation care (the 'actors'). Analyses showed a positive significant effect of high plan specificity and high plan enactment among those patients who consulted a 'pre-intender' GP (Table 5). Among the patients who consulted an 'intender' GP, both high and low plan specificities, as well as high plan enactment, had a positive effect on asking about smoking. In all the three patient subgroups, we found evidence for the combined effect of high plan specificity and high plan enactment on GP asking about smoking.

Table 4 Interaction effect of GP plan enactment and GP plan specificity on the provision of smoking cessation activities (patient-reported) $)^{a, b}$

\begin{tabular}{|c|c|c|c|c|c|}
\hline \multirow[b]{2}{*}{ Asked about smoking } & \multicolumn{2}{|c|}{ Baseline } & \multicolumn{2}{|c|}{ Post-intervention } & \multirow[t]{2}{*}{ Time $\times$ group OR $(95 \% \mathrm{Cl})$} \\
\hline & $n$ total & $\%$ asked & $n$ total & $\%$ asked & \\
\hline High PS $\times$ high PE & 359 & $36.5 \%$ & 221 & $57.5 \%$ & $3.08(2.04-4.64)^{* *}$ \\
\hline Low $\mathrm{PS} \times$ high $\mathrm{PE}$ & 100 & $24.0 \%$ & 93 & $43.0 \%$ & $3.00(1.54-5.86)^{*}$ \\
\hline High $P S \times$ low PE & 372 & $21.0 \%$ & 216 & $20.8 \%$ & $1.19(0.74-1.92)$ \\
\hline Low PS $\times$ low PE & 171 & $46.8 \%$ & 100 & $37.0 \%$ & $0.71(0.40-1.26)$ \\
\hline Control group & 1,066 & $40.8 \%$ & 703 & $37.1 \%$ & 1 \\
\hline
\end{tabular}

GPs general practitioners, $O R$ odds ratio, $C$ confidence interval, $P S$ plan specificity, $P E$ plan enactment.

ancludes all patients, both smokers and non-smokers $(n=3,401)$.

${ }^{\mathrm{b}}$ Generalised estimating equations adjusted for clustering and patient characteristics.

${ }^{*} p<0.01,{ }^{* *} p<0.001$. 
Table 5 Effect of specificity and enactment of GPs' plan on asking about smoking (patient-reported) among the three subgroups of patients who consulted 1) a pre-intender GP, 2) an intender GP, and 3) an actor GP ${ }^{a, b}$

\begin{tabular}{|c|c|c|c|c|c|c|c|c|c|}
\hline & \multicolumn{3}{|c|}{ GP pre-intender $(n=393)$} & \multicolumn{3}{|c|}{ GP intender $(n=2,211)$} & \multicolumn{3}{|c|}{ GP actor $(n=797)$} \\
\hline & $\begin{array}{l}\text { Pre } n \text { total } \\
\text { (\% asked) }\end{array}$ & $\begin{array}{l}\text { Post } \boldsymbol{n} \text { total } \\
\text { (\% asked) }\end{array}$ & $\begin{array}{l}\text { Time } \times \text { group } \\
\text { OR }(95 \% \mathrm{Cl})\end{array}$ & $\begin{array}{l}\text { Pre } n \text { total } \\
\text { (\% asked) }\end{array}$ & $\begin{array}{l}\text { Post } n \text { total } \\
\text { (\% asked) }\end{array}$ & $\begin{array}{l}\text { Time } \times \text { group } \\
\text { OR }(95 \% \mathrm{Cl})\end{array}$ & $\begin{array}{l}\text { Pre } n \text { total } \\
\text { (\% asked) }\end{array}$ & $\begin{array}{l}\text { Post } \boldsymbol{n} \text { total } \\
\text { (\% asked) }\end{array}$ & $\begin{array}{l}\text { Time } \times \text { group } \\
\text { OR }(95 \% \mathrm{Cl})\end{array}$ \\
\hline \multicolumn{10}{|l|}{ Plan specificity } \\
\hline High & 86 (20.9\%) & $32(68.8 \%)$ & $8.26(2.26-27.39)^{*}$ & 416 (31.0\%) & 274 (44.9\%) & $1.93(1.49-2.50)^{* *}$ & 229 (27.1\%) & 131 (20.6\%) & $0.82(0.48-1.40)$ \\
\hline Low & $9(33.3 \%)$ & $0(00.0 \%)$ & c & 163 (33.1\%) & $144(47.9 \%)$ & $2.03(1.38-2.99)^{* *}$ & $99(47.5 \%)$ & $49(16.3 \%)$ & $0.19(0.08-0.46)^{* *}$ \\
\hline Control group & $182(15.4 \%)$ & $84(10.7 \%)$ & 1 & 719 (40.1\%) & $495(40.8 \%)$ & 1 & $165(40.6 \%)$ & $124(32.3 \%)$ & 1 \\
\hline \multicolumn{10}{|l|}{ Plan enactment } \\
\hline High & $49(28.6 \%)$ & $21(90.5 \%)$ & $46.84(6.8-324.9)^{* *}$ & 256 (35.9\%) & $235(57.0 \%)$ & $2.80(2.02-3.89)^{* *}$ & $154(64.3 \%)$ & $58(72.4 \%)$ & $0.69(0.36-1.32)$ \\
\hline Low & $46(15.2 \%)$ & $11(27.3 \%)$ & $1.49(0.35-6.38)$ & $323(65.0 \%)$ & $183(61.2 \%)$ & $1.10(0.77-1.58)$ & $174(59.2 \%)$ & $122(80.3 \%)$ & $0.43(0.25-0.74)^{*}$ \\
\hline Control group & $182(10.0 \%)$ & $84(10.7 \%)$ & 1 & 719 (51.3\%) & $495(54.9 \%)$ & 1 & 165 (55.5\%) & $124(66.9 \%)$ & 1 \\
\hline \multicolumn{10}{|l|}{$P S \times P E$} \\
\hline High $\times$ high & $40(27.5 \%)$ & $21(90.5 \%)$ & $66.45(6.65-661.7)^{* *}$ & 204 (38.2\%) & 166 (59.0\%) & $9.78(3.90-24.53)^{* *}$ & 115 (36.5\%) & $34(29.4 \%)$ & $37.82(8.95-159.9)^{* *}$ \\
\hline Low $\times$ high & $9(33.3 \%)$ & $0(0.00 \%)$ & c & $52(26.9 \%)$ & $69(52.2 \%)$ & $4.78(2.04-11.19)^{* *}$ & $39(17.9 \%)$ & $24(16.7 \%)$ & $1.32(0.31-5.58)$ \\
\hline High $\times$ low & $46(15.2 \%)$ & $11(27.3 \%)$ & $1.94(0.32-11.77)$ & $212(24.1 \%)$ & 108 (23.2\%) & $1.09(0.58-2.03)$ & $114(17.5 \%)$ & $97(17.5 \%)$ & $2.04(0.83-5.02)$ \\
\hline Low $\times$ low & $0(0.00 \%)$ & $0(0.00 \%)$ & c & 111 (36.0\%) & 75 (44.0\%) & $1.60(0.80-3.20)$ & $60(66.7 \%)$ & 25 (16.0\%) & $0.14^{*}(0.04-0.54)$ \\
\hline Control group & $182(15.4 \%)$ & $84(10.7 \%)$ & 1 & 719 (44.1\%) & 495 (41.1\%) & 1 & 165 (40.6\%) & $124(32.3 \%)$ & 1 \\
\hline
\end{tabular}

GPs general practitioners, $P S$ plan specificity, $P E$ plan enactment, $O R$ odds ratio, $C l$ confidence interval.

${ }^{a}$ Includes all patients, both smokers and non-smokers $(n=3,401)$.

${ }^{\mathrm{b}}$ Generalised estimating equations adjusted for clustering and patient characteristics.

${ }^{c}$ Analyses not possible due to the sparseness of data.

${ }^{*} p<0.01,{ }^{* *} p<0.001$.

\section{Discussion}

\section{Main findings}

This study examined the effects of action planning and coping planning within a training programme for GPs on their provision of guideline-recommended smoking cessation care. In line with our previously reported effects of the GP training [50], the 25 GPs in the intervention group asked patients more often about smoking after formulating an action plan during the training compared to prior to the training. In line with our hypothesis, GPs who formulated a highly specific action plan asked their patients more often about smoking than GPs with less specific plans. Moreover, high plan specificity had a positive effect on GPs asking patients about smoking when they also highly enacted their plan. The effects of plan specificity and plan enactment were particularly present among GPs who initially intended to implement smoking cessation care but who had not yet routinely implemented such care. No effects of action planning, plan specificity, and plan enactment were found on GPs' provision of quit smoking advice and arranging follow-up for smokers who were motivated to quit. In addition, no effects were found of GP coping planning on arranging follow-up for smokers who were not motivated to quit.

\section{Interpretation of the findings}

Our finding that action planning incorporated in a training programme for GPs increased the extent to which these professionals asked their patients about smoking is in line with the earlier results on the positive effects of incorporating self-formulated conditional plans in an educational class for health-care professionals [35]. However, no evidence was found for GP action planning on GPs' provision of other tasks, such as advising to quit and arranging follow-up for smokers who were motivated to quit. This latter finding does not correspond with the general evidence for action planning on intended behaviours in patient samples [41-43]. Nevertheless, the percentage of smokers that was advised to quit smoking by GPs who formulated a highly specific-related post-intervention action plan was substantially larger compared to baseline (37.1\% versus 53.3\%). A comparable pattern was observed with regard to the percentage of smokers who were motivated to quit and for who a follow-up was arranged by the GP (15.4\% versus $40.0 \%)$. These substantial positive changes in time were not observed within the control group (advised to quit at baseline: $43.8 \%$ versus $44.1 \%$ post-intervention; arranged follow-up for smokers motivated to quit at baseline: $18.3 \%$ versus $9.6 \%$ post-intervention).

The small sample sizes may have impeded statistical confirmation of these findings. Another explanation for this may be that GPs might have more difficulty to act upon other action plans compared to merely asking their patients about smoking. The percentage of smokers who report being advised to quit or for who follow-up support was arranged, is indeed overall lower than the 
percentage of patients who were asked about their smoking behaviour. Smokers tend to express more resistance and negative statements about quitting when being advised to quit compared to being asked about their smoking behaviour [52,53]. In addition, GPs indicate that they lack an overview of health promotion programmes in their own neighbourhood to which they can refer their patients [5]. Therefore, GPs may derive more benefit from training in coping plans on how to deal with these difficulties. A second explanation might relate to the quality of the action plans, which has shown considerable variability in patient samples [17]. In the present study, although we rated the specificity of GPs' action plans, a specific plan does not necessarily mean a 'good' plan. Indeed, for maximal impact of a plan, GPs require the opportunity to enact the plan as often as possible. Other aspects of planning, such as opportunity, could be explored in future studies. A final explanation may be related to the lack of a prior power analysis, which could have described the power required to detect the intended effects.

Although coping planning anticipates potential barriers to behaviour (i.e. encountering smokers who are not motivated to quit), no effect of GPs' coping plan was found on their provision of guideline-recommended smoking cessation care to these smokers. The current guideline for smoking cessation care offers GPs a solution for this type of barrier, i.e. asking the smoker's permission to discuss their smoking behaviour during a subsequent consultation [1]. Of our 25 GPs, only six (24\%) formulated this guideline-recommended activity highly specific; this might indicate that not all GPs were familiar with this guideline-recommended solution, or that this solution may not be appropriate for all GPs. Additionally, GPs may face more specific obstacles, such as the resistance of smokers or lack of time to provide adequate smoking cessation care. Therefore, we recommend that future studies involve GPs in formulating their own obstacles and solutions to provide smoking cessation care. A volitional help sheet (providing a list of possible obstacles and behavioural responses) is often effective in translating individuals' intention into action and might also be a suitable tool for health-care professionals [45-48].

We also examined the effects of plan specificity and self-reported plan enactment on GPs' provision of smoking cessation care. In line with previous studies within patient samples, we found evidence for the positive effects of formulating a highly specific action plan on GPs' asking about smoking compared to a general action plan [31,51]. We also found evidence for GP-reported high plan enactment on the frequency with which GPs asked their patients about smoking. This latter finding is in line with de Vries et al. [33] and Ziegelmann et al. [34] who found that a self-reported plan enactment predicted smoking abstinence and an increase in physical activity, respectively. Moreover, our analyses showed that GPs were most likely to ask their patients about smoking when they enacted a highly specific formulated action plan. To our knowledge, this interaction effect has not yet been examined, and it provides additional insight into the mechanisms underlying action planning.

All the described effects were present among GPs who, at baseline, intended to implement smoking cessation care and were lacking among GPs who, at baseline, were already categorised as 'actors'. These findings are in line with the theories suggesting that action planning is a post-intentional strategy which aims to bridge the gap between the individual's intention to perform the behaviour and the actual performance of that behaviour $[54,55]$. At baseline, GPs who indicated that they had already fully implemented smoking cessation care in their practise may already have a clear idea of when, where, and how they will ask their patients about smoking. Indeed, highly conscientious individuals might benefit less from self-formulated conditional plans as they may already use such approaches [17]. As reported elsewhere, the GP training programme focused on increasing the GP's intention to implement smoking cessation care and succeeded therein [50]. This might explain why 'pre-intender' GPs also benefitted from action planning; however, the small size of this subgroup resulted in ORs with a wide confidence interval, indicating a low level of precision of this finding.

\section{Study strengths and weaknesses}

The strength of the present study is that it explored whether a training programme with action planning (a strategy proven effective in patient samples) increases the provision of guideline-recommended smoking cessation activities among GPs. In addition, we examined the specificity of the plans GPs made and the extent to which they enacted these plans; these aspects are often neglected within planning interventions [17]. In particular, we distinguished between GP-reported behaviour (plan enactment) and patient-reported outcomes (GP provision of smoking cessation care). There is an increasing interest in the effects of planning interventions on the clinical behaviour of health-care professionals [56]. The present study provides further insight into the feasibility of applying this strategy in a GP sample and generates new hypotheses that can be examined in future research.

Some limitations should also be mentioned. First, we assessed the effects of the GP training incorporating action planning on patient-reported smoking cessation activities of GPs. Patients may have perceived the GP's quit smoking advice or referral for follow-up support as being embedded in a general conversation about smoking behaviour; in that case, the smoking cessation activities of the GP might have escaped their attention. Such recall 
bias may have led to a lack of effect of action planning on the delivery of these smoking cessation activities. Secondly, the precise response rate of patients who completed the questionnaire (at baseline and postintervention) is unknown. Reasons for non-response might be attributed to GPs who failed to hand out the patient questionnaires or to patients who forgot or were unwilling to complete the questionnaire. Thirdly, the relatively small sample of GPs and smoking patients might have reduced the chance of detecting a true effect of action planning, plan speci58ficity, and/or plan enactment on GPs' provision of quit smoking advice and referrals. Also, we measured GPs' intention and plan enactment with single item measures. Further research is needed to examine the validity of these measures. Finally, during the study period, some of the GPs did not have direct access to the smoking cessation programmes of (trained) practise nurses, which may have contributed to the lack of effect on GPs' referrals.

\section{Conclusions}

Action planning within a training programme for GPs improves the frequency with which the GPs ask patients about their smoking. Action planning was particularly beneficial among those GPs who had a pre-existing intention to implement smoking cessation care. Importantly, a highly specific action plan that was well enacted was most likely to result in patients being asked about smoking by their GP. Since action planning did not improve the provision of other GP tasks regarding smoking cessation care, future studies should further examine the effects of coping plans on the provision of these GP tasks. These plans might help GPs to anticipate possible barriers that impede them from acting on their intentions. In addition, we recommend that our findings be replicated in randomised controlled studies with a larger GP sample and a long-term follow-up [57].

\section{Competing interests}

The authors declare that they have no competing interests.

\section{Authors' contributions \\ MV and MC contributed to the conception and design of the study, acquisition of the data, statistical analyses and interpretation of the data, drafting of the manuscript, and gave final approval for the submission of the manuscript. JP contributed to the interpretation of the data, drafting of the manuscript, and gave final approval for the submission of the manuscript. NC, MS, AK, and WA contributed to the conception and design of the study, drafting of the manuscript, and gave final approval for submission of the manuscript. All authors read and approved the final manuscript.}

\section{Acknowledgements}

This study was performed under MIRO, a national programme for optimising smoking cessation. MIRO is an initiative of Pfizer and Caphri. This project is supported by an unrestricted grant from Pfizer and Caphri.

\section{Author details}

${ }^{1}$ Department of Public Health and Primary Care, Leiden University Medical Centre, PO Box 9600, 2300, RC, Leiden, The Netherlands. ${ }^{2}$ Institute of Health and Society, Newcastle University, Baddiley-Clark Building, Richardson Road, Newcastle upon Tyne NE2 4AX, UK. Department of Medical Psychology, Leiden University Medical Centre, PO Box 9600, 2300, RC, Leiden, The Netherlands. ${ }^{4}$ Department of Primary and Community Care, Radboud University Nijmegen Medical Centre, PO Box 9101, 6500, HB, Nijmegen, The Netherlands.

Received: 30 May 2014 Accepted: 22 November 2014

Published online: 30 December 2014

\section{References}

1. Chavannes NH, Kaper J, Frijling BD, Van der Laan JR, Jansen PWM, Guerrouj S, Drenthen AJM, Bax W, Wind LA: Dutch College of General Practitioners guideline for smoking cessation [NHG-standaard stoppen met roken] Huisarts Wet 2007, 50:306-314.

2. Fiore M, Jaén CR, Baker TB, Bailey WC, Bennett G, Benowitz NL, Christiansen BA, Connell M, Curry SJ, Dorfman SF, Fraser D, Froelicher ES, Goldstein MG, Hasselblad V, Healton CG, Heishman S, Henderson PN, Heyman RB, Husten C, Koh HK, Kottke TE, Lando HA, Leitzke C, Mecklenburg RE, Mermelstein RJ, Morgan G, Mullen PD, Murray EW, Orleans CT, Piper ME, et al: A clinical practice guideline for treating tobacco use and dependence: 2008 update. A U.S. public health service report. Am J Prev Med 2008, 35:158-176.

3. Coleman T, Murphy E, Cheater F: Factors influencing discussion of smoking between general practitioners and patients who smoke: a qualitative study. Br J Gen Pract 2000, 50:207-210.

4. Coleman T, Cheater F, Murphy E: Qualitative study investigating the process of giving anti-smoking advice in general practice. Patient Education and Counselling 2004, 52:163.

5. Geense WW, van de Glind IM, Visscher TL, van Achterberg T: Barriers, facilitators and attitudes influencing health promotion activities in general practice: an explorative pilot study. BMC Fam Pract 2013, 14:20.

6. Stead M, Angus K, Holme I, Cohen D, Tait G: Factors influencing European GPs' engagement in smoking cessation: a multi-country literature review. Br J Gen Pract 2009, 59:682-690.

7. Vogt F, Hall S, Marteau TM: General practitioners' and family physicians' negative beliefs and attitudes towards discussing smoking cessation with patients: a systematic review. Addiction 2005, 100:1423-1431.

8. de Korte D, Nagelhout GE, Willemsen MC: Stoppen-met-rokenadvisering door huisartsen in Nederland 2001-2009. [Smoking cessation advisement in Dutch general practice: 2001-2009]. The Hague, the Netherlands. 2010. Available at http://stivoro.nl/wp-content/uploads/themapublicaties/stoppenmetroken adviezen/Themapublicatie\%20Stoppenmetrokenadvisering\%20door\% 20huisartsen\%20in\%20Nederland\%202001\%202009.pdf.

9. Pieterse ME, Seydel ER, de Vries H, Mudde AN, Kok GJ: Effectiveness of a minimal contact smoking cessation program for Dutch general practitioners: a randomized controlled trial. Prev Med 2001, 32:182-190.

10. Puschel K, Thompson B, Coronado G, Huang Y, Gonzalez L, Rivera S: Effectiveness of a brief intervention based on the ' $5 A^{\prime}$ ' model for smoking cessation at the primary care level in Santiago, Chile. Health Promot Int 2008, 23:240-250.

11. Takahashi K, Saso H, Saka H, Saso H, Iwata M, Hashimoto I, Naito M, Hamajima N: A pilot study on inducement of smoking cessation by a simple 5A (asking, advice, assess, assist, and arrange) approach at outpatient clinics. Asian Pac J Cancer Prev 2006, 7:131-135.

12. Davies P, Walker AE, Grimshaw JM: A systematic review of the use of theory in the design of guideline dissemination and implementation strategies and interpretation of the results of rigorous evaluations. Implement Sci 2010, 5:14.

13. Grimshaw JM, Thomas RE, MacLennan G, Fraser C, Ramsay CR, Vale L, Whitty P, Eccles MP, Matowe L, Shirran L, Wensing M, Dijkstra R, Donaldson C: Effectiveness and efficiency of guideline dissemination and implementation strategies. Health Technol Assess 2004, 8:1-72.

14. Mazza D, Bairstow P, Buchan H, Chakraborty SP, Van HO, Grech C, Kunnamo I: Refining a taxonomy for guideline implementation: results of an exercise in abstract classification. Implement Sci 2013, 8:32.

15. Medves J, Godfrey C, Turner C, Paterson M, Harrison M, MacKenzie L, Durando P: Systematic review of practice guideline dissemination and implementation strategies for healthcare teams and team-based practice. Int J Evid Based Healthc 2010, 8:79-89.

16. Bonetti D, Johnston M, Pitts NB, Deery C, Ricketts I, Tilley C, Clarkson JE: Knowledge may not be the best target for strategies to influence 
evidence-based practice: using psychological models to understand RCT effects. Int J Behav Med 2009, 16:287-293.

17. Sniehotta FF: Towards a theory of intentional behaviour change: plans, planning, and self-regulation. Br J Health Psychol 2009, 14:261-273.

18. Eccles MP, Grimshaw J, Walker A, Johnston M, Pitts N: Changing the behavior of healthcare professionals: the use of theory in promoting the uptake of research findings. J Clin Epidemiol 2005, 58:107-112.

19. Eccles MP, Hrisos S, Francis J, Kaner EF, Dickinson HO, Beyer F, Johnston M: Do self- reported intentions predict clinicians' behaviour: a systematic review. Implement Sci 2006, 1.

20. Godin G, Belanger-Gravel A, Eccles M, Grimshaw J: Healthcare professionals' intentions and behaviours: a systematic review of studies based on social cognitive theories. Implement Sci 2008, 3.

21. Michie S, Johnston M, Abraham C, Lawton R, Parker D, Walker A: Making psychological theory useful for implementing evidence based practice: a consensus approach. Qual Saf Health Care 2005, 14:26-33.

22. Perkins MB, Jensen PS, Jaccard J, Gollwitzer P, Oettingen G, Pappadopulos E, Hoagwood KE: Applying theory-driven approaches to understanding and modifying clinicians' behavior: what do we know? Psychiatr Serv 2007, 58:342-348

23. LEVENTHAL H, Watts JC, Pagano F: Effects of fear and instructions on how to cope with danger. J Pers Soc Psychol 1967, 6:313-321.

24. Leventhal H, SINGER R, JONES S: Effects of fear and specificity of recommendations upon attitudes and behavior. J Pers Soc Psychol 1965, 2:20-29.

25. Orbell S, Sheeran P: 'Inclined abstainers': a problem for predicting health-related behaviour. Br J Soc Psychol 1998, 37:151-165.

26. Sheeran P, Milne S, Webb TL, Gollwitzer PM: Implementation Intentions and Health Behaviour. In Predicting Health Behaviour Research and Practice With Social Cognition Models. 2nd edition. Berkshire, UK: Open University Press; 2005:276-323.

27. Parks-Stamm EJ, Gollwitzer PM, Oetingen G: Action control by implementation intentions: effective cue detection and efficient response initiation. Soc Cogn 2007, 25:248-266.

28. Webb TL, Sheeran P: Idenitifying good opportunities to act: implementation intentions and cue discrimination. Eur J Soc Psychol 2004, 34:407-419.

29. Webb TL, Sheeran P: How do implementation intentions promote goal attainment? A test of component processes. J Exp Soc Psychol 2007. 43:295-302.

30. Webb TL, Sheeran P: Mechanisms of implementation intention effects: the role of goal intentions, self-efficacy, and accessibility of plan components. Br I Soc Psychol 2008, 47:373-395.

31. de Vet E, Oenema A, Brug J: More or better: do the number and specificity of implementation intentions matter in increasing physical activity? Psychol Sport Exerc 2011, 12:471-477.

32. van Osch L, Lechner L, Reubsaet A, de Vries H: From theory to practice: an explorative study into the instrumentality and specificity of implementation intentions. Psychol Health 2010, 25:351-364.

33. de Vries H, Eggers SM, Bolman C: The role of action planning and plan enactment for smoking cessation. BMC Public Health 2013, 13:393.

34. Ziegelmann JP, Lippke S, Schwarzer R: Adoption and maintenance of physical activity: planning interventions in young, middle-aged, and older adults. Psychol Health 2006, 21:145-163.

35. Casper ES: Using implementation intentions to teach practitioners: changing practice behaviors via continuing education. Psychiatr Serv 2008, 59:747-752.

36. Eccles MP, Grimshaw JM, Johnston M, Steen N, Pitts NB, Thomas R, Glidewell E, MacLennan G, Bonetti D, Walker A: Applying psychological theories to evidence-based clinical practice: identifying factors predictive of managing upper respiratory tract infections without antibiotics. Implement Sci 2007, 2:26.

37. Grimshaw JM, Eccles MP, Steen N, Johnston M, Pitts NB, Glidewell L, MacLennan G, Thomas R, Bonetti D, Walker A: Applying psychological theories to evidence-based clinical practice: identifying factors predictive of lumbar spine $\mathrm{x}$-ray for low back pain in UK primary care practice. Implement Sci 2011, 6:55.

38. Presseau J, Johnston M, Heponiemi T, Elovainio M, Francis JJ, Eccles MP, Steen N, Hrisos S, Stamp E, Grimshaw JM, Hawthorne G, Sniehotta FF: Reflective and automatic processes in health care professional behaviour: a dual process model tested across multiple behaviours. Ann Behav Med 2014, 48:347-358.
39. Pipe A, Sorensen M, Reid R: Physician smoking status, attitudes toward smoking, and cessation advice to patients: an international survey. Patient Educ Couns 2009, 74:118-123.

40. Young JM, Ward JE: Implementing guidelines for smoking cessation advice in Australian general practice: opinions, current practices, readiness to change and perceived barriers. Fam Pract 2001, 18:14-20.

41. Adriaanse MA, Vinkers CD, De Ridder DT, Hox JJ, De Wit JB: Do implementation intentions help to eat a healthy diet? A systematic review and meta-analysis of the empirical evidence. Appetite 2011, 56:183-193.

42. Bélanger-Gravel A, Godin G, Amireault S: A meta-analytic review of the effect of implementation intentions on physical activity. Health Psychol Rev 2013, 7:23-54.

43. Gollwitzer PM, Sheeran P: Implementation intentions and goal achievement: a meta-analysis of effects and processes. Adv Exp Soc Psychol 2006, 38:69-119.

44. Sniehotta FF, Scholz U, Schwarzer R: Action plans and coping plans for physical exercise: a longitudinal intervention study in cardiac rehabilitation. Br J Health Psychol 2006, 11:23-37.

45. Armitage CJ, Arden MA: A volitional help sheet to reduce alcohol consumption in the general population: a field experiment. Prev Sci 2012, 13:635-643.

46. Arden MA, Armitage $\mathrm{CJ}$ : A volitional help sheet to reduce binge drinking in students: a randomized exploratory trial. Alcohol Alcohol 2012, 47:156-159.

47. Armitage CJ: A volitional help sheet to encourage smoking cessation: a randomized exploratory trial. Health Psychol 2008, 27:557-566.

48. Armitage CJ, Arden MA: A volitional help sheet to increase physical activity in people with low socioeconomic status: a randomised exploratory trial. Psychol Health 2010, 25:1129-1145.

49. Fiore MC, Wetter DW, Bailey WC, Bennett G, Cohen SJ, Dorfman SF, Goldstein MG, Gritz ER, Hasselblad V, Henningfield JE, Heyman RB, Holbrook J, Husten C, Jaen CR, Kohler C, Kottke TE, Lando HA, Manley M, Mecklenburg R, Melvin C, Mullen PD, Nett LM, Piasecki TM, Robinson L, Rothstein D, Schriger DL, Stitzer ML, Stachenko S, Tommasello S, Villejo L, et al: The agency for health care policy and research smoking cessation clinical practice guideline. J Am Med Assoc 1996, 275:1270-1280.

50. Verbiest MEA, Crone MR, Scharloo M, Chavannes NH, van der Meer V, Kaptein AA, Assendelft WJJ: One-hour training for general practitioners in reducing the implementation gap of smoking cessation care: a clusterrandomized controlled trial. Nicotine Tob Res 2013, 16:1-10.

51. van Osch $L$, Reubsaet $A$, Lechner $L$, de Vries $H$ : The formation of specific action plans can enhance sun protection behavior in motivated parents. Prev Med 2008, 47:127-132

52. Pilnick A, Coleman T: "I'll give up smoking when you get me better": patients' resistance to attempts to problematise smoking in general practice (GP) consultations. Soc Sci Med 2003, 57:135-145.

53. Verbiest MEA, Chavannes NH, Passchier E, Noordman J, Scharloo M, Kaptein AA, Assendelft WJJ, Crone MR: Sequence-analysis of video-recorded practitioner-patient communication about smoking in general practice: do smokers express negative statements about quitting? Pat Educ Couns 2014, 97:352-360

54. Gollwitzer PM: Implementation intentions: strong effects of simple plans. Am Psychol 1999, 54:493-503.

55. Sniehotta FF, Scholz U, Schwarzer R: Bridging the intention-behaviour gap: planning, self-efficacy, and action control in the adoption and maintenance of physical exercise. Psychol Health 2005, 20:143-160.

56. Squires J, Presseau J, Francis J, Bond CM, Fraser C, Patey A, Porteous T, Vachon B, Tonelli M, Yu CHY, Grimshaw J: Self-formulated conditional plans for changing health behaviour among healthcare consumers and health professionals. Cochrane Database Syst Rev 2013, 12:CD010869. doi:10.1002/14651858.CD010869.

57. Presseau J, Hawthorne G, Sniehotta FF, Steen N, Francis JJ, Johnston M, Mackintosh J, Grimshaw JM, Kaner E, Elovainio M, Deverill M, Coulthard T, Brown H, Hunter M, Eccles MP: Improving diabetes care through examining, advising, and prescribing (IDEA): protocol for a theory-based cluster randomised controlled trial of a multiple behaviour change intervention aimed at primary healthcare professionals. Implement Sci 2014, 9:61. 